\title{
Tomato Cell Death Mediated By Complementary Plant Viral Satellite RNA Sequences
}

\author{
Michael E. Taliansky, Eugene V. Ryabov, David J. Robinson, and Peter Palukaitis \\ Virology Department, Scottish Crop Research Institute, Invergowrie, Dundee DD2 5DA, Scotland \\ Accepted 18 August 1998
}

\begin{abstract}
Cell death (necrosis) and severe yellowing (chlorosis) in tomato are induced by cucumber mosaic virus (CMV) supporting particular satellite RNAs. To determine whether CMV RNA sequences also are needed to induce necrosis or chlorosis, tomato seedlings were infected with the potato virus $X$ vector expressing either a necrogenic or chlorosis-inducing satellite RNA of CMV. The infected plants did not develop chlorosis, although they did develop necrosis, but only when all or part of a 335-nucleotide necrogenic satellite RNA was expressed in the (-) polarity; i.e., the strand not packaged in virus particles. Computerassisted secondary structure analysis suggests that the necrogenicity domain is an octanucleotide loop and adjacent base-paired stem of a thermodynamically stable hairpin structure.
\end{abstract}

Additional keywords: replication, RNA structure, synergy.

Plants often respond to infection by a pathogen with the development of a hypersensitive response in which the pathogen is either confined or restricted by a localized necrotic reaction (Keen 1990). It is less common for plant pathogens to induce cell death that spreads throughout the plant, resulting in systemic lethal necrosis, although alterations in either pathogen genes (Kim and Palukaitis 1997) or plant genes (Mur et al. 1997) can affect the extent of cell death observed. In at least one pathogen-host combination, the development of a systemic necrosis was observed late in infection, rather than coincident with pathogen movement, and was induced by an RNA sequence, rather than an encoded protein. This necrosis was induced by satellite RNAs of cucumber mosaic virus (CMV), consisting of approximately 330 to 400 nucleotides (Roossinck et al. 1992).

Satellite RNAs are parasites of plant viruses, depending on their helper viruses for both replication and encapsidation, and usually attenuating the disease induced by the helper virus (reviewed by Roossinck et al. 1992). However, some satellite RNAs of CMV exacerbate the pathogenicity in specific hosts (Roossinck et al. 1992). For example, a lethal necrosis of tomato plants in Japan (Kosaka et al. 1989) and several Mediterranean countries (Kaper and Waterworth 1977; Gallitelli et al. 1988; Jordá et al. 1992; Škoric et al. 1996) was caused by CMV in association with particular satellite RNAs. In addition, yellow chlorosis of tobacco in Japan (Takanami 1981),

Corresponding author: Peter Palukaitis; Fax: 44-1382-562426; E-mail: ppaluk@scri.sari.ac.uk and a white-leaf disease as well as a yellow chlorosis on tomato in New York State (Gonsalves et al. 1982; Palukaitis 1988) have been shown to involve satellite RNAs of CMV.

Specific satellite RNA sequences involved in induction of cell death in tomato (Masuta and Takanami 1989; Sleat and Palukaitis 1990a; Devic et al. 1990; Sleat et al. 1994) as well as chlorosis in either tobacco or tomato (Jaegle et al. 1990; Kuwata et al. 1991; Sleat and Palukaitis 1992; Zhang et al. 1994) have been identified. However, the molecular mechanisms by which some but not other satellite RNAs of CMV enhance pathogenicity remain unknown. Various secondary structure models for satellite RNAs have been proposed (Gordon and Symons 1983; García-Arenal et al. 1987; Hidaka et al. 1988; Tousignant and Kaper 1993), but in general it has not been possible to clearly attribute differences in pathology to differences in satellite RNA structure. Recent, refined secondary structure analyses of two satellite RNAs inducing cell death in tomato (Bernal and García-Arenal 1997; RodriguezAlvarado and Roossinck 1997) and the first determination of a satellite RNA structure in planta as well as within virus particles (Rodriguez-Alvarado and Roossinck 1997) suggested the most probable structural context of the necrogenicity domain.

The helper virus, CMV, is an isometric virus with a positive-sense (i.e., messenger) RNA genome, encompassing five genes expressed from three genomic and two subgenomic RNAs (reviewed by Palukaitis et al. 1992; Ding et al. 1994). The 111-kDa 1a protein encoded by CMV RNA 1 contains sequence motifs present in methyl transferases and helicases, while the $97-\mathrm{kDa} 2 \mathrm{a}$ protein encoded by RNA 2 contains sequences present in viral polymerases. Together with associated host protein(s), the 1a and $2 \mathrm{a}$ proteins of CMV form the viral replicase (Hayes and Buck 1990). The 13-kDa 2b protein encoded by RNA 2 is believed to be involved in virus movement in some hosts (Ding et al. 1995b). The 30-kDa 3a protein is an RNA-binding protein involved in virus cell-to-cell movement (Ding et al. 1995a; Kaplan et al. 1995; Li and Palukaitis 1996; Canto et al. 1997), and the 25-kDa 3b protein is the viral coat protein (Habili and Francki 1974), which is also required for virus movement (Suzuki et al. 1991; Canto et al. 1997). Most strains (biologically differentiable isolates) of CMV do not contain satellite RNAs, but induce their own pathological responses, which are altered in the presence of satellite RNAs.

In some instances, the satellite RNA-mediated pathogenicity has been shown to be affected by the strain of helper virus (Lee and Kummert 1985; Kaper et al. 1990; Sleat and Palukaitis 1990b; Wu and Kaper 1992; Sleat et al. 1994). For cer- 
tain specific CMV:satellite RNA combinations, RNA 2 of CMV has been shown to be involved in determining the pathogenicity specificity (Sleat and Palukaitis 1990b; Sleat et al. 1994). However, for other satellite RNAs of CMV the involvement of the (CMV) helper virus sequences in satellite RNA-mediated cell death is less clear. Thus, while it is apparent that CMV and specific satellite RNAs interact to induce the various chlorotic responses, it is uncertain whether the helper virus has a specific role in tomato cell death, beyond amplifying the satellite RNA sequences and transporting them throughout the plant.

To ascertain whether CMV RNA sequences are needed to induce cell death, sequences of a necrogenic satellite RNA and, as a control, a chlorosis-inducing satellite RNA were expressed from an unrelated virus, potato virus $\mathrm{X}$ (PVX), which has been used as a vector for expression of "foreign" genes in plants (Chapman et al. 1992; Baulcombe et al. 1995; Hammond-Kosack et al. 1995; Culver 1996; English et al. 1996). The PVX vector enabled complete and partial sequences of the CMV satellite RNA to be amplified and assessed for pathogenicity in the absence of the natural helper virus.

\section{RESULTS}

\section{Necrosis induction in tomato by (-) satellite RNA sequences.}

cDNAs corresponding to CMV satellite RNAs were inserted into plasmids containing the PVX vector sequences, such that the satellite RNA sequences would be amplified during the replication of PVX RNA. In addition, CMV satellite RNAs also would be expressed in two subgenomic RNAs derived from the virus vector, which are generated to allow expression of internal genes of PVX (Chapman et al. 1992).

The necrogenic satellite RNA, D4-sat RNA (Kurath and Palukaitis 1989), was expressed in two orientations: one in which the $(+)$ polarity strand, which is packaged (encapsidated) in CMV particles, (+) D4-sat RNA, was in the same orientation as the virion or mRNA-sense (+) PVX RNA (referred to as PVX-D4[+]), and one in which the nonencapsidated (-) polarity RNA strand, (-) D4-sat RNA, was produced as part of the (+) PVX RNA (referred to as PVXD4[-]) (Fig. 1). Tomato plants inoculated with PVX-D4(+) showed only a mild mottle disease and a few chlorotic flecks, similar to plants inoculated with unmodified PVX (Fig. 2A and $\mathrm{C})$. RNA extracted from tomato plants infected with PVX-D4(+) contained PVX RNA and the expected subgenomic RNAs, as well as D4-sat RNA sequences, whereas plants infected with PVX alone contained PVX RNA sequences but not D4-sat RNA sequences (Fig. 3A and C). Furthermore, the level of PVX RNA was comparable in both types of infected plant, indicating that the presence of CMV satellite RNA sequences did not suppress accumulation of PVX RNA, as it does CMV RNA when CMV is the helper virus (Kaper et al. 1990; Roossinck et al. 1992). Unexpectedly, when PVX-D4(-) (Fig. 1) was inoculated to tomato plants, cell death was observed (Fig. 2D and E). The extent of cell death was variable: some plants were killed (Fig. 2E), as occurs when tomato plants were infected with CMV and D4sat RNA (Kurath and Palukaitis 1989; Sleat and Palukaitis 1990a; Sleat et al. 1994), but in other plants, only a few leaves were affected and subsequently the plants did not develop le- thal necrosis (Fig. 2D; as in Masuta and Takanami 1989; Wu and Kaper 1992; Sleat et al. 1994). The pattern of PVX subgenomic RNAs detected in these new leaves showed that they contained PVX sequences both with and without the D4-sat RNA sequences (Fig. 3B). The tendency of some sequences to be eliminated from the PVX vector has been noted (Chapman et al. 1992; Hammond-Kosack et al. 1995; Culver 1996). The levels of accumulated D4-sat RNA and PVX RNA sequences were similar, whether (+) D4-sat RNA or (-) D4-sat RNA sequences were expressed from PVX (Fig. 3A and C).

Expression of the non-necrogenic B5-sat RNA sequences (Kurath and Palukaitis 1989) from the PVX vector in either orientation did not induce cell death in tomato (Fig. 1), although both PVX and satellite RNA sequences could be detected (Fig. 3A and C). Hence, cell death in tomato was not due simply to infection by PVX expressing any CMV satellite RNA.

\section{Necrosis induction in tomato by the $5^{\prime}$ half of (-) satellite RNA.}

B/D-sat and D/B-sat RNAs are chimeric satellite RNAs constructed from cDNA clones of B5-sat RNA and D4-sat RNA. These were used previously to localize the necrogenic sequences to the $3^{\prime}$ half of the (+) D4-sat RNA; i.e., B/D-sat RNA, but not D/B-sat RNA, induced cell death in tomato (Kurath and Palukaitis 1989). These chimeric satellites were introduced into PVX in either orientation (Fig. 1), and were assessed for pathogenicity in tomato. PVX-D/B(+), PVX$\mathrm{B} / \mathrm{D}(+)$, and $\mathrm{PVX}-\mathrm{D} / \mathrm{B}(-)$ did not induce cell death (Figs. 1 and $2 \mathrm{~F}$ and $\mathrm{L}$ ), although all three viruses replicated efficiently in tomato and to the same level as PVX-B/D(-) (Fig. 3A and C). However, PVX-B/D(-) induced cell death (Figs. 1 and $2 \mathrm{G})$ that varied in extent, as did that induced by PVX-D4(-). These data further demonstrated that the RNA sequences in

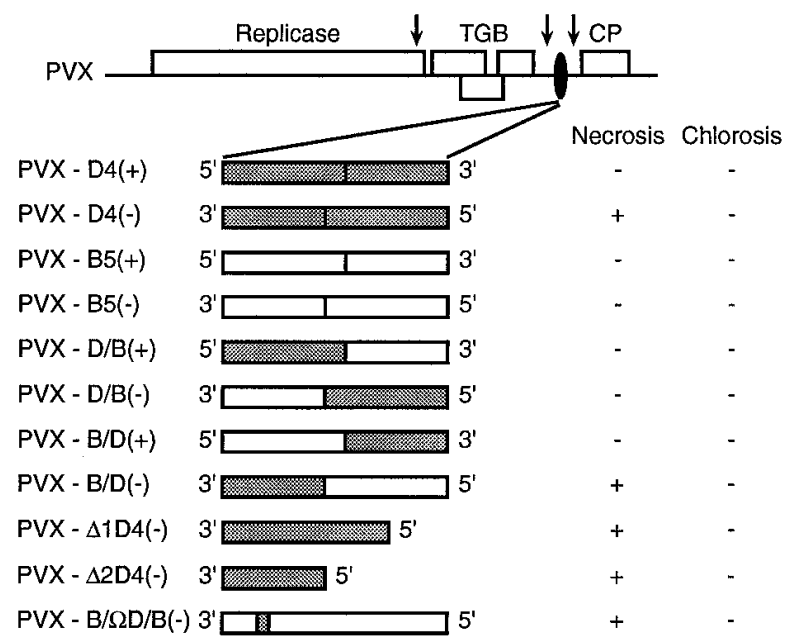

Fig. 1. Induction of cell death or chlorosis in tomato by potato virus $X$ (PVX) vectors expressing cucumber mosaic virus (CMV) satellite RNA sequences. Genome organization of PVX, the site of insertion of the various satellite sequences derived from D4-sat RNA, B5-sat RNA, or chimeras $\mathrm{B} / \mathrm{D}$ and $\mathrm{D} / \mathrm{B}$, orientation, (+) or $(-)$, of satellite RNA sequences expressed in (+) PVX RNA, and pathogenicity of each derivative are indicated. RNA transcripts were inoculated to tomato cv. Rutgers plants to assess infectivity of PVX transcripts and induction of cell death or chlorosis by satellite RNA sequences. Arrows indicate locations of subgenomic RNA promoter sequences used by the PVX replicase to allow expression of internal genes. 
the $5^{\prime}$ half of the (-) D4-sat RNA induced cell death in tomato. These sequences are complementary to the $3^{\prime}$ half of the (+) D4-sat RNA, to which the necrogenicity domain previously was mapped (Kurath and Palukaitis 1989; Sleat and Palukaitis 1990a; Sleat et al. 1994).

To ascertain whether the entire satellite RNA molecule is necessary for necrosis induction, tomato plants were inocu- lated with PVX expressing either the $5^{\prime}$ three-fourths or $5^{\prime}$ half of (-) D4-sat RNA (PVX- $\Delta \mathrm{l}$ D4[-] and PVX- $\Delta 2 \mathrm{D} 4[-]$, respectively; Fig. 1). In both cases, necrotic lesions were observed in systemically infected tomato leaves (Fig. $2 \mathrm{H}$ and I), demonstrating that sequences and/or structures in the $3^{\prime}$ half of the (-) D4-sat RNA molecules are dispensable for induction of cell death in tomato.
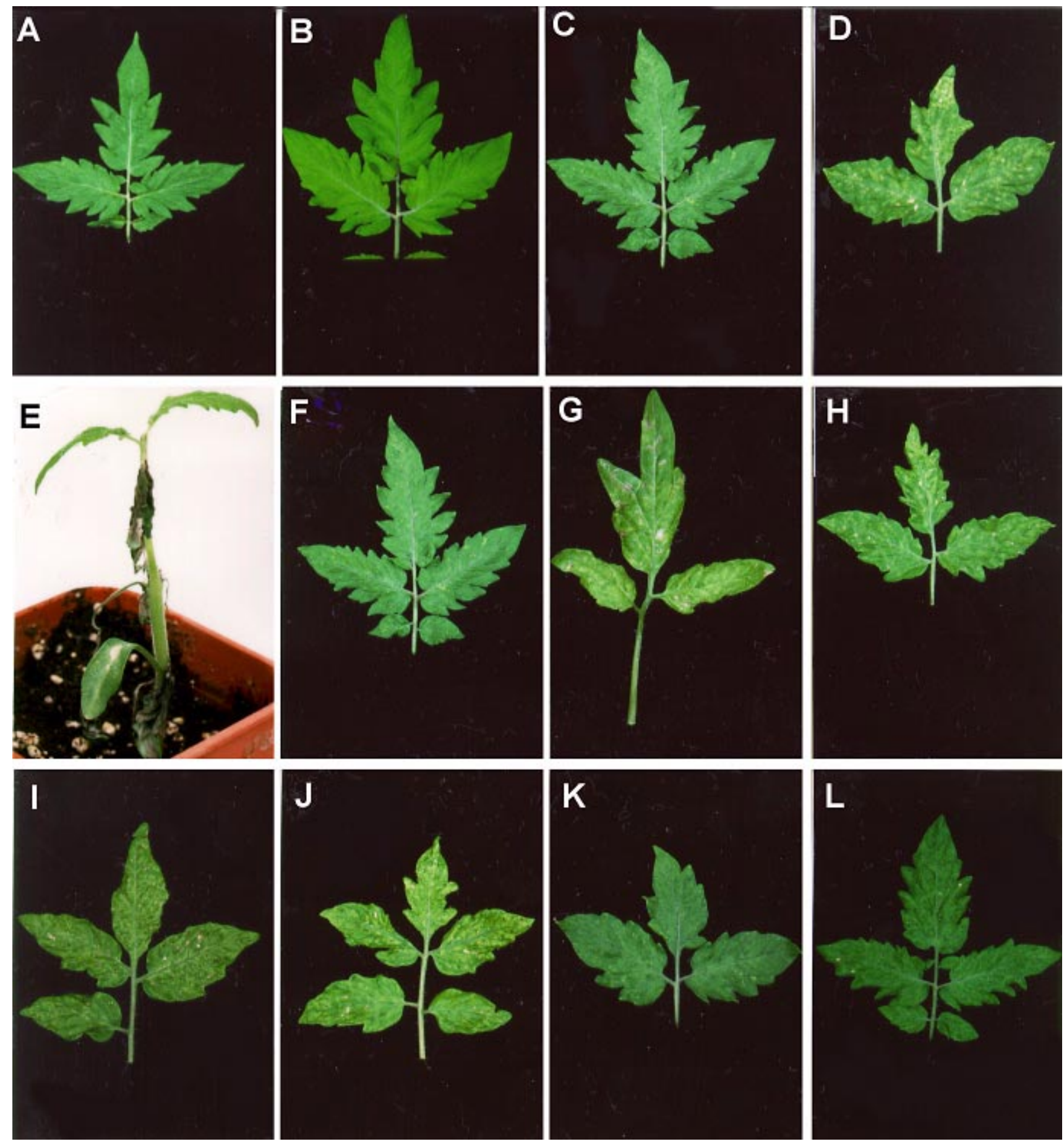

Fig. 2. Pathology in tomato plants inoculated with unmodified potato virus $X(P V X)$ RNA (A) or PVX containing various cucumber mosaic virus (CMV) satellite RNA sequences: C, PVX-D4(+); D and E, PVX-D4(-); F, PVX-B/D(+); G, PVX-B/D(-); H, PVX- $\Delta 2 \mathrm{D} 4(-)$; I, PVX- $\Delta 1 \mathrm{D} 4(-)$; J, PVX$\mathrm{B} / \Omega \mathrm{D} / \mathrm{B}(-)$; K, PVX-B5(-); L, PVX-D/B(-). A mock-inoculated control plant is shown in B. Inocula indicated for each panel were as described in Figure 1. Photographs were taken 2 to 3 weeks after inoculation. 
Effect of sequence alterations on cell death in tomato.

Specific sequences involved in necrosis induction have been identified, leading to the delineation of a core necrosis domain (Masuta and Takanami 1989; Devic et al. 1990; Sleat and Palukaitis 1990a) on the (+) satellite RNA. The corresponding sequences of the necrogenic (-) D4-sat RNA differ from those of the non-necrogenic (-) B5-sat RNA at several positions within this domain (Fig. 4). To demonstrate the influence of these sequences on the induction of necrosis in tomato, the sequences in this domain were modified in PVXB5(-) to contain the sequences present in PVX-D4(-) (Fig. 4) and tomato plants were infected with PVX containing (-) RNA of the modified satellite RNA (PVX-B/ $2 \mathrm{D} / \mathrm{B}[-]$ in Fig. 1). Specifically, (-) B5-sat RNA sequences 43 to 55 were replaced with (-) D4-sat RNA sequences 43 to 52 (Fig. 4) to generate $\mathrm{B} / \Omega \mathrm{D} / \mathrm{B}$-sat RNA. The tomato plants inoculated with $\mathrm{PVX}-\mathrm{B} / \Omega \mathrm{D} / \mathrm{B}(-)$ developed necrotic lesions (Figs. 1 and $2 \mathrm{~J}$ ), as was observed for various PVX derivatives expressing all or part of (-) D4-sat RNA (Fig. 2J versus D, E, G, H, and I). This confirms that the same sequences are involved in necrosis induction by satellite RNAs expressed from PVX as in satellite RNA supported by CMV, and that CMV sequences are not required for necrosis induction.

\section{Effect of satellite RNA level on cell death in tomato.}

During the replication of PVX-D4(+), (-) D4-sat RNA sequences also are generated within the complementary PVX RNA ([-] PVX RNA), although at a much lower level than when the (-) D4-sat RNA is present in the (+) PVX RNA (i.e., in PVX-D4[-]); the usual ratio of (+):(-) viral RNA in infected plants is 20 to 100:1. Potato virus Y (PVY) has been shown to increase the level of PVX (+) and (-) RNAs in tobacco by twoto sixfold and 10- to 15-fold, respectively (Vance 1991), resulting in a worse disease than caused by either virus alone, i.e., viral synergy (Rochow and Ross 1955). Thus, tomato seedlings were inoculated with PVY and PVX-D4(+) RNA to determine whether synergy could increase the concentration of (-) D4-sat RNA present in the (-) PVX RNA generated from PVX-D4(+) RNA to a level sufficient to induce cell death. While no synergy in pathology was observed in the doubly inoculated plants, a three- to fourfold increase in PVX concentration was detected serologically (data not shown). Dot-blot hybridization analysis of nucleic acids extracted from the doubly infected tomato plants showed that the level of (+) D4-sat RNA sequences had increased threefold over the level observed in the plants inoculated by PVX-D4 (+) alone, similar to the level of (+) D4-sat RNA present during infection by CMV and D4-sat RNA (Table 1). By contrast, the level of (-) D4-sat RNA sequences had increased 12-fold (Table 1). Tomato plants inoculated with PVY and PVX-D4 (-) showed a comparable stimulation in the level of accumulated (+) and (-) D4-sat RNA sequences (Table 1) although once again there was no increase in the extent of cell death in the tomato plants (data not shown). These data indicate that increasing the level of (-) D4-sat RNA expressed from PVX-D4(+) in the presence of PVY by an order of magnitude did not induce cell death.

Chlorosis induction in tomato by CMV satellite sequences.

The B5-sat RNA induces a bright, yellow chlorosis in tomato (Kurath and Palukaitis 1989; Sleat and Palukaitis 1992). When PVX expressing the B5-sat RNA in either (+) or (-) orientation (PVX-B5[+] and PVX-B5[-]; Fig. 1) was inoculated to tomato plants, chlorosis was not observed (Figs. 1 and 2L). Similarly, chlorosis was not observed when PVX expressing D4-sat RNA, B/D-sat RNA, or D/B-sat RNA was inoculated to tomato plants (Figs. 1 and $2 \mathrm{~F}, \mathrm{G}$, and $\mathrm{L}$ ), indicating that the CMV helper virus is required for chlorosis induction. CMV was not coinoculated with either PVX-B5(+) or PVX-B5(-) to ascertain whether co-replication of CMV and PVX expressing B5-sat RNA sequences would induce chlorosis, since it had been shown that satellite RNAs flanked by nonviral sequences and expressed in transgenic plants (Baulcombe et al. 1986; Jacquemond et al. 1988; Masuta et al. 1989; Tousch et al. 1994), from a plasmid (Jacquemond and Lauquin 1988), or as RNA transcripts (Tousch et al. 1994) could be amplified and packaged by CMV, with loss of the non-satellite flanking sequences.

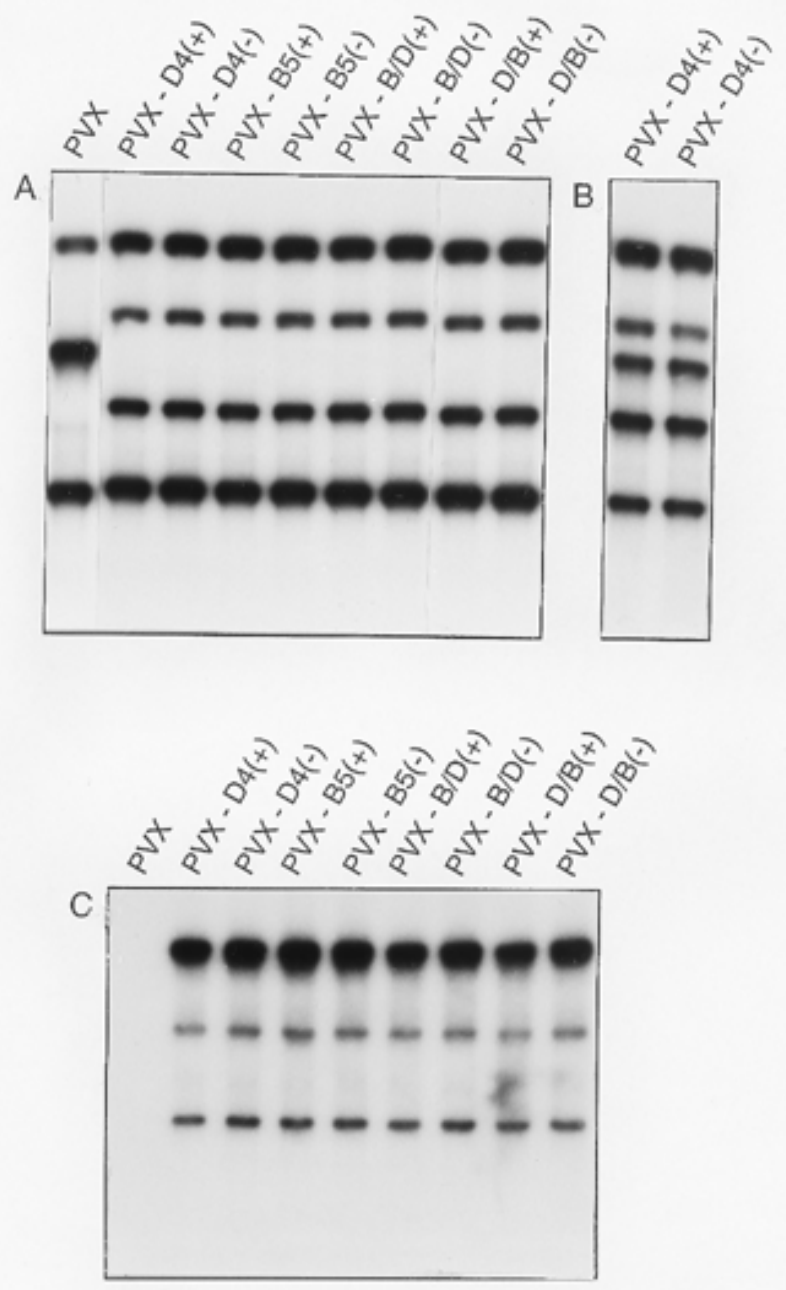

Fig. 3. Accumulation of potato virus $X(P V X)$ RNA and cucumber mosaic virus (CMV) satellite RNA sequences in tomato. Cotyledons of tomato seedlings were inoculated with transcripts as indicated at top of each lane of autoradiograms. Total nucleic acids were extracted from (A, C) first or second true leaves or (B) from leaves higher on the plants. Nucleic acids were analyzed by electrophoresis in $1.5 \%$ agarose gels and Northern (RNA) blot hybridization with ${ }^{32} \mathrm{P}$-labeled cDNA probes specific to either (A, B) PVX RNA or (C) CMV satellite RNA sequences. Top band in each track represents PVX genomic RNA; other bands represent subgenomic RNAs originating from promoters shown in Figure 1. Samples were taken from plants after photography (Fig. 2). 


\section{DISCUSSION}

\section{Satellite RNA-induced pathogenicity in tomato.}

The inability of the B5-sat RNA sequences to induce chlorosis when expressed from the PVX vector supports earlier conclusions that $\mathrm{CMV}$ is involved in some interaction leading to chlorosis induction (Sleat and Palukaitis 1990b). The satellite RNA sequences involved in chlorosis induction in either tobacco or tomato in the presence of the CMV helper mapped to a different half of the satellite RNA molecule from those satellite RNA sequences involved in induction of cell death in tomato (Kurath and Palukaitis 1989; Masuta and Takanami 1989; Devic et al. 1989, 1990; Jaegle et al. 1990). Moreover, if the sequences specifying chlorosis induction in tomato and necrosis induction in tomato were present in the same satellite RNA (e.g., the B/D-sat RNA chimera; Fig. 1), then both chlorosis and cell death were manifested, although the latter was delayed until after the expression of the former (Kurath and Palukaitis 1989). While these results indicate the presence of separate elicitors for these host responses, apparently there was some interference of one (cell death) by the other (chlorosis). Previous studies had ruled out open reading frames of the (+) sense satellite RNAs being involved in these two pathogenic reactions (Collmer and Kaper 1988; Masuta and Takanami 1989; Devic et al. 1990; Jaegle et al. 1990).

\section{Cell death in tomato.}

Infection by PVX-D4(+) did not induce cell death, although $(-)$ D4-sat RNA sequences were produced as part of the $(-)$ PVX RNA synthesized during replication of PVX-D4(+). However, it seems plausible that the level of (-) D4-sat RNA sequences was not sufficient to induce cell death when generated in (-) PVX RNA. This is supported by the inability of PVXD4(+) to induce necrosis even in the presence of PVY, when the level of (-) D4-sat RNA contained with (-) PVX RNA increased 12-fold (Table 1). Moreover, the level of (-) D4-sat RNA was similar during infection by either PVX-D4 (-) or CMV plus D4-sat RNA (Table 1). This suggests that a certain threshold concentration of specific (-) satellite RNA sequence may be required for induction of cell death. In addition, the variation in the extent of necrosis observed here and in other studies (Kaper et al. 1990; Wu and Kaper 1992; Sleat et al. 1994) suggests there may be particular stages in the development of tomato plants when these plants are more susceptible to induction of cell death. This may in part explain the failure to observe cell death when necrogenic satellite RNAs were supported by some strains of CMV (Lee and Kummert 1985; Kaper et al. 1990; Wu and Kaper 1992; Sleat et al. 1994). In two of those studies, either no necrosis (Kaper et al. 1990), or only partial necrosis (Wu and Kaper 1992) was observed in plants containing reduced levels of (-) satellite RNA, measured as double-stranded (ds) RNA, although the levels of single-stranded (+) satellite RNA were similar.

It is interesting to note that extracts from plants infected by CMV together with a satellite RNA contain large quantities of ds satellite RNA (Diaz-Ruíz and Kaper 1977; Habili and Kaper 1981; Piazzolla et al. 1982). The ds RNAs forms of (+) sense viral RNAs are believed to be an artefact of extraction, the two strands normally being separated by proteins in the cell.

Table 1. Comparison of levels of $(+)$ and (-) satellite RNA accumulating from potato virus X (PVX)-D4(+) and PVX-D4(-) with and without potato virus Y (PVY), versus when supported by cucmber mosaic virus (CMV)

\begin{tabular}{lcc}
\hline & \multicolumn{2}{c}{ Level of RNA $^{\mathbf{a}}$} \\
\cline { 2 - 3 } Inoculum & D4(+) & D4(-) \\
\hline Experiment 1 & & \\
PVX-D4(+) & $48 \pm 4$ & 1 \\
PVX-D4(+) + PVY & $144 \pm 9$ & $12 \pm 2$ \\
PVX-D4(-) & 1 & $45 \pm 6$ \\
PVX-D4(-) + PVY & $8 \pm 1$ & $130 \pm 11$ \\
Experiment 2 & $44 \pm 3$ & 1 \\
PVX-D4(+) & 1 & $49 \pm 4$ \\
PVX-D4(-) & $132 \pm 12$ & $32 \pm 5$ \\
Fny-CMV+D4-sat RNA &
\end{tabular}

${ }^{a}$ RNA levels in relative units: average of triplicate samples \pm standard deviation. RNA levels were determined by densitometry of dot blot hybridization data obtained with cRNA probes specific to $(+)$ or $(-)$ D4-sat RNA.
D4-sat

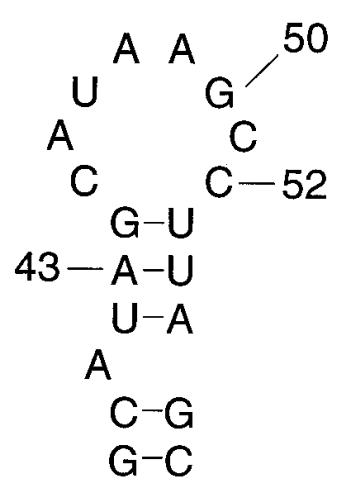

B5-sat

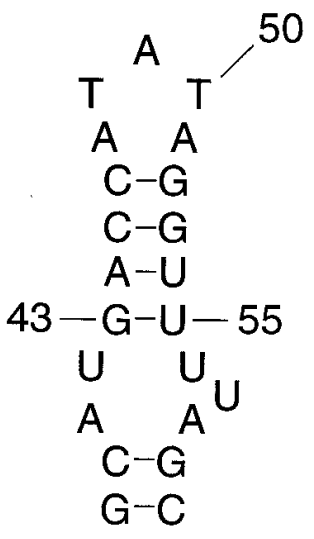

$\mathrm{B} / \Omega \mathrm{D} / \mathrm{B}-\mathrm{sat}$

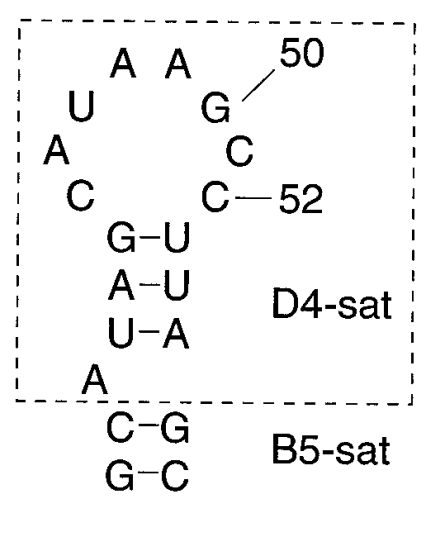

Fig. 4. RNA sequence and putative stem-loop secondary structure of a specific segment of (-) satellite RNAs. RNA sequence of (-) D4-sat RNA from nucleotides 39 to 57 and (-) B5-sat RNA from nucleotides 39 to 60 is presented as loop and upper stem of a stem-loop structure (see Figure 5). In (-) $\mathrm{B} / \Omega \mathrm{D} / \mathrm{B}$-sat RNA, the nucleotides 43 to 55 in (-) B5-sat RNA were replaced with the nucleotides 43 to 52 in (-) D4-sat RNA. D4-sat RNA and all other necrogenic satellite RNAs do not contain the trinucleotide represented by (-) B5-sat RNA sequences 46 to 48. 
Whether this is also the case for satellite RNAs of CMV is less clear (Habili and Kaper 1981; Kuroda et al. 1997). However, in contrast to the usual 20 to 100:1 ratio for $(+):(-)$ viral RNAs, the ratio of (+):(-) CMV satellite RNA in extracts from infected plants can be 2 to $4: 1$ (Table 1; Piazzolla et al. 1982). Thus, plants infected by CMV and a necrogenic satellite RNA produce large quantities of the non-encapsidated (-) satellite RNA as well as the encapsidated (+) satellite RNA, and the data presented here show that it is the (-) satellite RNA that induces cell death, even in the absence of the helper virus, CMV.

Could the observed cell death be elicited by a small protein encoded by (-) satellite RNA sequences? The $5^{\prime}$ half of (-) D4-sat RNA has an open reading frame encoding a 20 amino acid polypeptide (data not shown). However, some other necrogenic satellite RNAs have a frameshift immediately after the initiator methionine, resulting in the encoding of a 9 amino acid polypeptide with a different putative sequence (not shown). This makes it highly unlikely that a satellite-encoded protein is responsible for the cell death.

\section{Secondary structure of (-) satellite RNA and tomato cell death.}

Various data support the influence of RNA secondary structure on the induction of cell death in tomato $(\mathrm{Wu}$ and Kaper 1992; Tousignant and Kaper 1993; Sleat et al. 1994). However, secondary structure analyses of satellite RNAs have been limited to the (+) satellite RNA molecule. An examination of putative secondary structures for several (-) satellite RNAs reveals that the sequences identified as forming the core of the necrogenicity domain (Figs. 4 and 5) are located in the loop and ascending stem of a stem-loop structure for the necrogenic satellite RNAs (-) D4-sat RNA (Kurath and Palukaitis 1987) and (-) Y-sat RNA (Masuta and Takanami 1989; Devic et al. 1990), as well as the chimera (-) W/D:279-sat RNA (Sleat et al. 1994), but not for the necrogenic satellite RNAs (-) WM2-sat RNA (Sleat and Palukaitis 1990a) (Fig. 5 and data not shown). However, if only the $5^{\prime} 160$ nucleotides of the (-) satellite RNAs are used for structural analysis, then the most stable structures of all of these satellite RNAs contain the same core sequences of the necrogenicity domain in the octanucleotide loop and adjacent stem of an elongated hairpin structure (Figs. 4 and 5, as well as data not shown). By contrast, the non-necrogenic satellite RNA, (-) B5-sat RNA, contains a different nucleotide sequence in the pentanucleotide loop of the hairpin structure (Figs. 4 and 5), while the three nucleotides differentiating the non-necrogenic (-) WL47-sat RNA (Kurath and Palukaitis 1989) from the necrogenic (-)

Fig. 5. Computer-generated secondary structures of (-) satellite RNA sequences. Predicted secondary structures are for complete (-) sequence of necrogenic D4-sat RNA, W/D:279-sat RNA, WM2-sat RNA, $\mathrm{B} / \Omega \mathrm{D} / \mathrm{B}$-sat, and the non-necrogenic B5-sat RNA, as well as for the 5' 160 nucleotides of (-) WM2-sat RNA. Ability to induce cell death, and presence of described hairpin structure and necrogenicity domain are indicated, as is the location of the necrosis-inducing domain (arrows), which is not present in B5-sat RNA. Necrosis-inducing domain is $5^{\prime}$ AUAGCAUAAGCC 3' (sequence in octanucleotide loop is underlined). Comparable sequences of WL47-sat RNA are 5' AUAaCcUAAGuC 3' (sequence in octanucleotide loop is underlined). Comparable sequences of B5-sat RNA are 5' AUGACCAUAUAGG 3' (sequence in pentanucleotide loop is underlined).
WM2-sat RNA (Sleat and Palukaitis 1990a) are located within and immediately adjacent to the octanucleotide loop (arrows in Figure 5). A mutant designated WM3-sat RNA, which did not induce cell death in tomato (Sleat and Palukaitis 1990a), was one nucleotide different from WM2-sat RNA, resulting in the first paired residues in the stem below the octanucleotide loop being A-U (in WM3-sat RNA) instead of GU (in WM2-
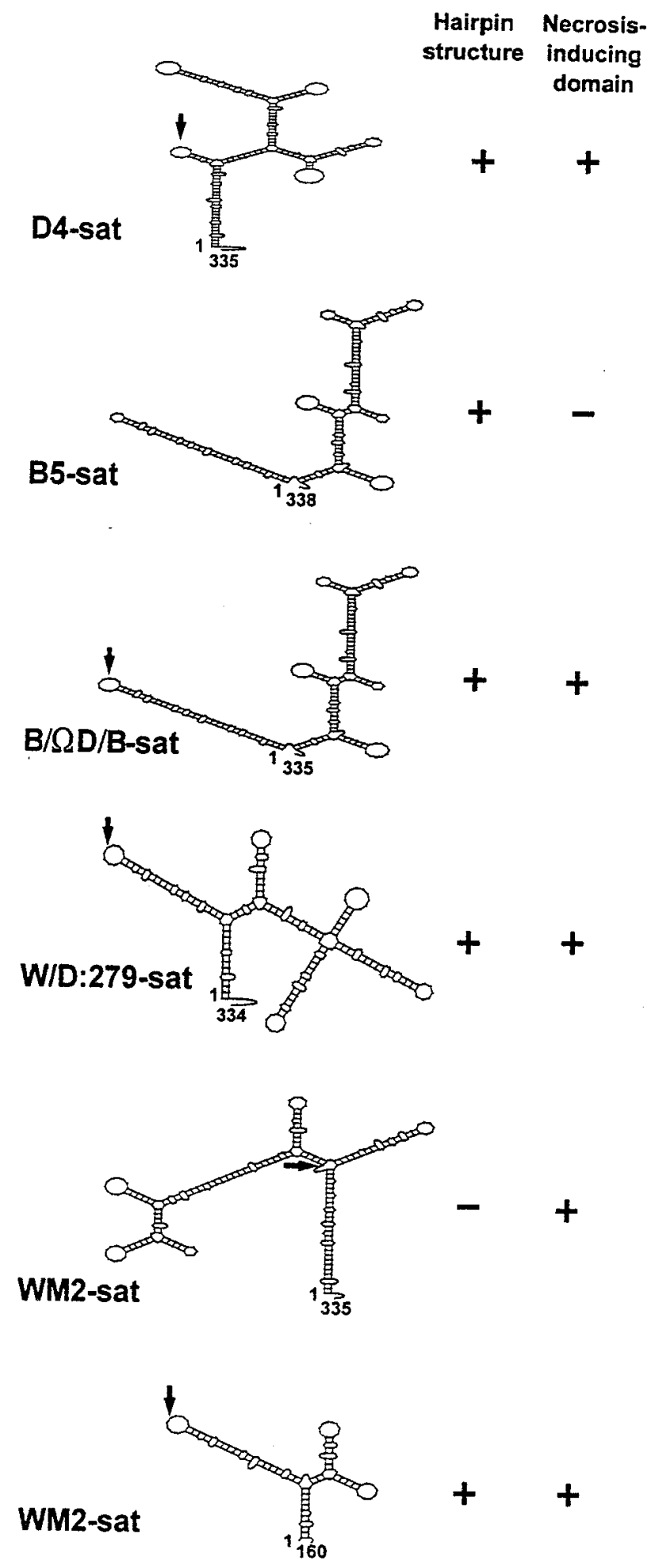
sat RNA). This indicates that the sequences within the upper stem are also important to induction of cell death. Alteration of the nucleotide sequences within the loop and in the adjacent stem of (-) B5-sat RNA to the corresponding sequences of $(-)$ D4-sat RNA (Fig. 4) changed the pathogenicity of the construct $(\mathrm{PVX}-\mathrm{B} / \Omega \mathrm{D} / \mathrm{B}[-])$ from non-necrogenic to necrogenic (Fig. 1). These sequence changes were predicted not to alter the base-pairing of the remaining, long base-paired stem of (-) B5-sat RNA (Fig. 5). Thus, it is proposed that the sequences in this loop and adjacent stem, present in the necrogenic satellite RNAs, either in the full-length folded molecule or in a structure encompassing only the $5^{\prime}$ half of the (-) satellite RNA, are the elicitor of the response leading to cell death. These sequences (structures) would have to be present at a high enough level during some early phase of plant growth to induce cell death, and parameters that affect the level of $(-)$ satellite RNA synthesis, such as temperature (White et al. 1995) and/or helper virus strain (Kaper et al. 1990; Wu and Kaper 1993; Kaper et al. 1995), would affect the ability of the (-) satellite RNA to induce cell death.

Programmed cell death is considered to be associated with the expression of particular genes (Jones and Dangl 1996). Although it is not clear whether the necrosis observed here is the same as programmed cell death, the demonstration here of species-specific cell death induced by an RNA molecule suggests that mechanisms exist for particular RNA sequences or structures to program cell death. This might be worthy of consideration when expressing (nontranslatable) transgenes or their antisense sequences in heterologous organisms.

\section{MATERIALS AND METHODS}

\section{Generation of chimeric cDNA constructs and mutants.}

Standard DNA manipulation techniques (Sambrook et al. 1989) were used for generation of chimeric cDNA constructs and mutants. The CMV satellite RNA inserts were obtained from the cDNA clones pDsat4, pBsat5, pBDsat185, and pDBsat185 (Kurath and Palukaitis 1989) by digestion with restriction endonucleases, and were ligated into compatible (or blunt end) sites after similar digestion of the cloned PVX cDNA vector, pP3C2S (Baulcombe et al. 1995), as shown in Table 2.

Fragments containing either the $3^{\prime}$ three-fourths or the $3^{\prime}$ half of the D4-sat cDNA insert were amplified by polymerase chain reaction with the pDsat4 plasmid as a template and oligonucleotides 5' - G C G C G T C G A C G G C G G G T T G

Table 2. Potato virus $\mathrm{X}$ (PVX) cDNA constructs containing satellite cDNA inserts

\begin{tabular}{lcc}
\hline Construct $^{\mathbf{a}}$ & Source of fragment and sites $^{\mathbf{b}}$ & PVX vector sites $^{\mathbf{c}}$ \\
\hline $\mathrm{pPVX}-\mathrm{D}(+)$ & $\mathrm{pDsat} 4$, SalI/SmaI & SalI/SmaI \\
$\mathrm{pPVX}-\mathrm{D}(-)$ & $\mathrm{pDsat} 4$, SalI/SmaI & EcoRV/SalI \\
$\mathrm{pPVX}-\mathrm{B}(+)$ & $\mathrm{pBsat} 5$, EcoRI/SalI & EcoRV/SalI \\
$\mathrm{pPVX}-\mathrm{B}(-)$ & $\mathrm{pBsat} 5$, EcoRI/SalI & SalI/SmaI \\
$\mathrm{pPVX}-\mathrm{D} / \mathrm{B}(+)$ & $\mathrm{pDBsat} 185$, PvuII/SalI & EcoRV/SalI \\
$\mathrm{pPVX}-\mathrm{D} / \mathrm{B}(-)$ & $\mathrm{pDBsat} 185$, PvuII/SalI & SalI/SmaI \\
$\mathrm{pPVX}-\mathrm{B} / \mathrm{D}(+)$ & $\mathrm{pBDsat} 185$, EcoRI/SalI & EcoRV/SalI \\
$\mathrm{pPVX}-\mathrm{B} / \mathrm{D}(-)$ & $\mathrm{pBDsat} 185$, EcoRI/SalI & SalI/SmaI \\
\hline
\end{tabular}

${ }^{a}$ Constructs shown in Figure 1.

${ }^{\mathrm{b}}$ Restriction endonucleases used to isolate full-length satellite cDNA inserts from the particular satellite cDNA construct.

${ }^{c}$ Restriction endonuclease sites in the potato virus X (PVX) vector into which the full-length satellite cDNA sequences were inserted.
A G T G A T G T T C C - 3' or 5'- G C G C G T C G A C C C C G C T C A G T T T G C T A G C A G - 3' containing Sall sites (underlined) and nucleotides 85 to 104 or nucleotides 170 to 191 of D4-sat as forward primers, respectively, and oligonucleotide 5' - G C G C C G G C C G G G T C C T G C A G A G G A A T G A T A G - 3' with an EagI site preceding 21 nucleotides complementary to those at the $3^{\prime}$ end of the D4-sat molecule as a reverse primer. Amplified fragments were cloned between the EagI and SalI sites of the PVX cDNA vector to give $\mathrm{pPVX}-\Delta 1 \mathrm{D} 4(-)$ and $\mathrm{pPVX}-\Delta 2 \mathrm{D} 4(-)$.

Replacement of nucleotides 43 to 55 in the minus strand of B5-sat RNA sequence for the corresponding sequence of D4-sat RNA (nucleotides 43 to 52) was done by overlap extension PCR (Higuchi et al. 1988) with the plasmid pPVX-B(-) as a template and two mutagenic oligonucleotides, 5'- G A T C A G C A T A G C A T A A G C C T T A G C C T C T C C C T G - 3' and 5' G G A G A G G C T A A G G C T T A T G C T A T G C T G A T C T C C - 3'. The fragment obtained was re-cloned into the $\mathrm{PVX}$ cDNA vector to give $\mathrm{pPVX}-\mathrm{B} / \Omega \mathrm{D} / \mathrm{B}(-)$.

\section{In vitro transcription and plant inoculation.}

Plasmids carrying modified PVX sequences were linearized with the restriction enzyme SpeI and in vitro transcripts were synthesized with T7 RNA polymerase, with the mCAP RNA Capping Kit (Stratagene, La Jolla, CA). Transcripts were inoculated directly to leaves of 3- to 4-week-old tomato cv. Rutgers plants by rubbing Corundum-dusted cotyledons with the transcription products derived from $0.2 \mu \mathrm{g}$ of plasmid template (per plant). For mixed infections with CMV, the transcripts were coinoculated with a suspension of total viral RNA of the Fny or LS strains of CMV ( $2 \mu \mathrm{g}$ per plant). For double infections with PVY, cotyledons of tomato plants preinoculated with the transcripts of recombinant PVX RNA were challenged 2 days later by inoculation with the O strain of PVY.

Transcription of pDsat 4 plasmid was carried out as de scribed above but without a cap analog. The transcript representing sequence of D4-sat RNA was coinoculated with the Fny strain of CMV on tobacco plants. Extracts obtained from these plants, 2 weeks post inoculation, were used for inoculation of tomato plants.

\section{Extraction and analysis of viral RNAs.}

Total single-stranded plant RNAs were extracted by the method of Blok et al. (1994). For dot blot hybridization analysis, samples of total plant RNA were spotted onto Hybond $\mathrm{N}$ nylon membrane (Amersham, Little Chalfont, UK) and immobilized by UV crosslinking in a Stratalinker 2400 (Stratagene). Hybridizations were done with cRNA probes transcribed from positive and negative strands of cDNA clones representing the complete nucleotide sequence of D4sat RNA, as described by Sambrook et al. (1989), with the following modification: RNA samples were denatured in 0.3 $\mathrm{M} \mathrm{NaOH}$ at room temperature for $1 \mathrm{~min}$ and then were neutralized with $0.3 \mathrm{M}$ acetic acid. These stringent conditions were required to denature ds PVX RNAs. Quantitative analysis of dot blots was done by densitometry of the autoradiographic images, with an Intelligent Quantifier, version 2.5.0 (Bio Image, Ann Arbor, MI). A dilution series of (+) and (-) D4-sat RNA transcripts was used as a concentration standard. For Northern (RNA) blot hybridization analysis, total plant RNA preparations were denatured with formaldehyde 
and formamide. Electrophoresis was in $1.5 \%$ agarose gels as outlined in Sambrook et al. (1989). RNA was transferred to Hybond $\mathrm{N}$ membrane by the capillary method with $50 \mathrm{mM}$ $\mathrm{NaOH}$ and immobilized by UV crosslinking.

Hybridizations probes were labeled with ${ }^{32} \mathrm{P}$-dATP with a Random Primers DNA Labelling Kit (Life Technologies, Gaithersburg, MD). PVX-specific probes were prepared from the SmaI (nucleotide 5699)-SpeI (nucleotide 6548) fragment of pP3C2S (PVX), which represents sequences toward the $3^{\prime}$ end of the PVX genome (coat protein gene). CMV sat-RNAspecific probes were prepared from the complete sat-RNA insert of pD4sat (SalI-SmaI fragment). ${ }^{32} \mathrm{P}$-labeled RNA probes specific to (+) or (-) D4-sat RNA sequences were prepared by transcription of pDsat4 plasmid as previously described (Kurath and Palukaitis 1987).

\section{Secondary structure analysis of RNA.}

Secondary structure analysis of RNA was done with the Fold RNA and Squiggles programs of the Wisconsin Genetics Computer Group (GCG, Madison, WI) sequence analysis software package.

\section{ACKNOWLEDGMENTS}

We thank D. Baulcombe, Sainsbury Laboratory, for use of the PVX vector $\mathrm{pP} 3 \mathrm{C} 2 \mathrm{~S}$. This work was supported by the Scottish Office Agriculture, Environment and Fisheries Department (SOAEFD) and Royal Society and EMBO Fellowships (to E. V. R.), and was done under license no. GM/57/1997 from SOAEFD.

\section{LITERATURE CITED}

Baulcombe, D. C., Chapman, S., and Santa Cruz, S. 1995. Jellyfish green fluorescent protein as a reporter for virus infection. Plant J. 7: 1045-1053.

Baulcombe, D. C., Saunders, G. R., Bevan, H. W., Mayo, M. A., and Harrison, B. D. 1986. Expression of biologically active viral satellit-e RNA from the nuclear genome of transformed plants. Nature 321: 446-449.

Bernal, J. J., and García-Arenal, F. 1997. Analysis of the in vitro secondary structure of cucumber mosaic virus satellite RNA. RNA 3:10521067

Blok, V. C., Ziegler, A., Robinson, D. J., and Murant, A. F. 1994. Sequences of 10 variants of the satellite-like RNA-3 of groundnut rosette virus. Virology 202:25-32.

Canto, T., Prior, D. A. M., Hellwald, K.-H., Oparka, K. J., and Palukaitis, P. 1997. Characterization of cucumber mosaic virus. IV. Movement protein and coat protein are both essential for cell-to-cell movement of cucumber mosaic virus. Virology 237:237-248.

Chapman, S., Kavanagh, T., and Baulcombe, D. C. 1992. Potato virus X as a vector for gene expression in plants. Plant J. 2:549-557.

Collmer, C. W., and Kaper, J. M. 1988. Site-directed mutagenesis of potential protein-coding regions in expressible cloned cDNAs of cucumber mosaic viral satellites. Virology 163:293-298.

Culver, J. N. 1996. Tobamovirus cross protection using a potexvirus vector. Virology 226:228-235.

Devic, M., Jaegle, M., and Baulcombe, D. 1989. Symptom production on tobacco and tomato is determined by two distinct domains of the satellite RNA of cucumber mosaic virus (strain Y). J. Gen. Virol. 70: 2765-2777

Devic, M., Jaegle, M., and Baulcombe, D. 1990. Cucumber mosaic virus satellite RNA (strain Y): Analysis of sequences which affect systemic necrosis on tomato. J. Gen. Virol. 71:1443-1449.

Diaz-Ruíz, J. R., and Kaper, J. M. 1977. Cucumber mosaic virusassociated RNA 5. III Little nucleotide sequence homology between CARNA 5 and helper RNA. Virology 80:204-213.

Ding, B., Li, Q., Nguyen, L., Palukaitis, P., and Lucas, W. J. 1995a. Cucumber mosaic virus 3a protein potentiates cell-to-cell trafficking of
CMV RNA in tobacco plants. Virology 207:345-353.

Ding, S. W., Anderson, B. J., Haase, H. H., and Symons, R. H. 1994 New overlapping gene encoded by the cucumber mosaic virus genome. Virology 198:593-601.

Ding, S. W., Li, W. X., and Symons, R. H. 1995b. A novel naturally occurring hybrid gene encoded by a plant RNA virus facilitates long distance virus movements. EMBO J. 14:5762-5772.

English, J. J., Mueller, E., and Baulcombe, D. C. 1996. Suppression of virus accumulation in transgenic plants exhibiting silencing of nuclear genes. Plant Cell 8:179-188.

Gallitelli, D., Di Franco, A., Vovlas, C., and Kaper, J. M. 1988. Mixed infections of CMV potyviruses in vegetable crops in southern Italy. Inf. Fitopatol. 38:57-64.

García-Arenal, F., Zaitlin, M., and Palukaitis, P. 1987. Nucleotide sequence analysis of six satellite RNAs of cucumber mosaic virus: Primary sequence and secondary structure alterations do not correlate with differences in pathogenicity. Virology 158:339-347.

Gonsalves, D., Provvidenti, R., and Edwards, M. C. 1982. Tomato white leaf: The relation of an apparent satellite RNA and cucumber mosaic virus. Phytopathology 72:1533-1538.

Gordon, K. H. J., and Symons, R. H. 1983. Satellite RNA of cucumber mosaic virus forms a secondary structure with partial $3^{\prime}$-terminal homology to genomal RNAs. Nucleic Acids Res. 11:947-960.

Habili, N., and Francki, R. I. B. 1974. Comparative studies on tomato aspermy and cucumber mosaic virus. I. Physical and chemical properties. Virology 57:392-401.

Habili, N., and Kaper, J. M. 1981. Cucumber mosaic virus-associated RNA 5. VII. Double-stranded form accumulation and disease attenuation in tobacco. Virology 122:250-261.

Hammond-Kosack, K. E., Staskawicz, B. J., Jones, J. D. G., and Baulcombe, D. C. 1995. Functional expression of a fungal avirulence gene from a modified potato virus X genome. Mol. Plant-Microbe Interact. 8:181-185.

Hayes, R. J., and Buck, K. W. 1990. Complete replication of a eukaryotic virus RNA in vitro by a purified RNA-dependent RNA polymerase. Cell 63:363-368.

Hidaka, S., Hanada, K., Ishikawa, K., and Miura, K. 1988. Complete nucleotide sequence of two new satellite RNAs associated with cucumber mosaic virus. Virology 164:326-333.

Higuchi, R., Krummel, B., and Saiki, R. K. 1988. A general method of in vitro preparation and specific mutagenesis of DNA fragments: Study of protein and DNA interactions. Nucleic Acids Res. 16:7351-7367.

Jacquemond, M., Anselem, J., and Tepfer, M. 1988. A gene coding for a monomeric form of cucumber mosaic virus satellite RNA confers tolerance to CMV. Mol. Plant-Microbe Interact. 1:311-316.

Jacquemond, M., and Lauquin, J.-H. 1988. The cDNA of cucumber mosaic virus-associated satellite RNA has in vivo biological properties. Biochem. Biophys. Res. Commun. 151:388-395.

Jaegle, M., Devic, M., Longstaff, M., and Baulcombe, D. C. 1990. Cucumber mosaic virus satellite RNA Y strain: Analysis of sequences which affect yellow mosaic symptoms on tobacco. J. Gen. Virol. 71: 1905-1912.

Jones, A. M., and Dangl, J. L. 1996. Logjam at the Styx: Programmed cell death in plants. Trends Plant Sci. 1:114-119.

Jordá, C., Alfaro, A., Aranda, M. A., Moriones, E., and García-Arenal, F. 1992. Epidemic of cucumber mosaic virus plus satellite RNA in tomatoes in eastern Spain. Plant Dis. 76:363-366.

Kaper, J. M., Geletka, L. M., Wu, G. S., and Tousignant, M. E. 1995. Effect of temperature on cucumber mosaic virus satellite-induced lethal tomato necrosis is helper virus strain dependent. Arch. Virol. 140:65-74.

Kaper, J. M., Tousignant, M. E., and Geletka, L. M. 1990. Cucumbermosaic-virus-associated RNA 5. XII: Symptom-modulating effect is codetermined by the helper virus satellite replication support function. Res. Virol. 141:487-503.

Kaper, J. M., and Waterworth, H. E. 1977. Cucumber mosaic virus associated RNA 5: Casual agent for tomato necrosis. Science 196:429-431.

Kaplan, I. B., Shintaku, M. H., Li, Q., Zhang, L., Marsh, L. E., and Palukaitis, P. 1995. Complementation of movement defective mutants in transgenic tobacco expressing the cucumber mosaic virus movement gene. Virology 209:188-199.

Keen, N. T. 1990. Gene-for-gene complementarity in plant-pathogen interactions. Annu. Rev. Genet. 24:447-463.

Kim, C.-H., and Palukaitis, P. 1997. The plant defense response to cu- 
cumber mosaic virus in cowpea is elicited by the viral polymerase gene and affects virus accumulation in single cells. EMBO J. 16 : 4060-4068

Kosaka, Y., Hanada, K., Fukunishi, T., and Tochihara, H. 1989. Cucumber mosaic virus isolate causing tomato necrotic disease in Kyoto prefecture. Ann. Phytopathol. Soc. Jpn. 55:229-232.

Kurath, G., and Palukaitis, P. 1987. Biological activity of T7 transcripts of a prototype clone and a sequence variant clone of a satellite RNA of cucumber mosaic virus. Virology 159:199-208.

Kurath, G., and Palukaitis, P. 1989. Satellite RNAs of cucumber mosaic virus: Recombinants constructed in vitro reveal independent functional domains for chlorosis and necrosis in tomato. Mol. PlantMicrobe Interact. 2:91-96.

Kuroda, T., Natsuaki, T., Wang, W.-Q., and Okuda, S. 1997. Formation of multimers of cucumber mosaic virus satellite RNA. J. Gen. Virol. 78:941-946.

Kuwata, S., Masuta, C., and Takanami, Y. 1991. Reciprocal phenotype alterations between two satellite RNAs of cucumber mosaic virus. J. Gen. Virol. 72:2385-2390.

Lee, H. S., and Kummert, J. 1985. Induction of tomato necrosis by cucumoviruses, as related to specific interactions between genomic and satellite RNAs. Parasitica 41:45-55.

Li, Q., and Palukaitis, P. 1996. Comparison of the nucleic acid and NTP binding properties of the movement proteins of cucumber mosaic cucumovirus and tobacco mosaic tobamovirus. Virology 216:71-79.

Masuta, C., Komari, T., and Takanami, Y. 1989. Expression of cucumber mosaic virus satellite RNA from cDNA copies in transgenic tobacco plants. Ann. Phytopathol. Soc. Jpn. 55:49-55.

Masuta, C., and Takanami, Y. 1989. Determination of sequence and structural requirements of pathogenicity of a cucumber mosaic virus satellite RNA (Y-sat RNA). Plant Cell 1:1165-1173.

Mur, L. A. J., Bi, Y.-M., Darby, R. M., Firek, S., and Draper, J. 1997. Compromising early salicylic acid accumulation delays the hypersensitive response and increases viral dispersal during lesion establishment in TMV-infected tobacco. Plant J. 12:1113-1126.

Palukaitis, P. 1988. Pathogenicity regulation by satellite RNAs of cucumber mosaic virus: Minor nucleotide sequence changes alter host responses. Mol. Plant-Microbe Interact. 1:175-181.

Palukaitis, P., Roossinck, M. J., Dietzgen, R. G., and Francki, R. I. B. 1992. Cucumber mosaic virus. Adv. Virus Res. 41:281-348.

Piazzolla, P., Tousignant, M. E., and Kaper, J. M. 1982 Cucumber mosaic virus-associated RNA 5. IX. The overtaking of viral RNA synthesis by CARNA 5 and dsCARNA 5 in tobacco. Virology 122:147-157.

Rochow, W. F., and Ross, A. F. 1955. Virus multiplication in plants doubly infected by potato viruses $\mathrm{X}$ and $\mathrm{Y}$. Virology 1:10-27.

Rodriguez-Alvarado, G., and Roossinck, M. J. 1997. Structure analysis of a necrogenic strain of cucumber mosaic cucumovirus satellite RNA in planta. Virology 236:155-166.

Roossinck, M. J., Sleat, D., and Palukaitis, P. 1992. Satellite RNAs of plant viruses: Structures and biological effects. Microbiol. Rev. 56:
265-279.

Sambrook, J., Fritsch, E. F., and Maniatis, T. A. 1989. Molecular Cloning: A Laboratory Manual. Cold Spring Harbor Laboratory, Cold Spring Harbor, NY.

Škoric, D., Krajacic, M., Barbarossa, L., Cillo, F., Grieco, F., Šaric, A., and Gallitelli, D. 1996. Occurrence of cucumber mosaic cucumovirus with satellite RNA in lethal necrosis affected tomatoes in Croatia. J. Phytopathol. 144:593-549.

Sleat, D. E., and Palukaitis, P. 1990a. Site-directed mutagenesis of a plant viral satellite RNA changes its phenotype from ameliorative to necrogenic. Proc. Natl. Acad. Sci. USA 87:2946-2950.

Sleat, D. E., and Palukaitis, P. 1990b. Induction of tobacco chlorosis by certain cucumber mosaic virus satellite RNAs is specific to subgroup II helper strains. Virology 176:292-295.

Sleat, D. E., and Palukaitis, P. 1992. A single nucleotide change within a plant virus satellite RNA alters the host specificity of disease induction. Plant J. 2:43-49.

Sleat, D. E., Zhang, L., and Palukaitis, P. 1994. Mapping determinants within cucumber mosaic virus and its satellite RNA for the induction of necrosis in tomato plants. Mol. Plant-Microbe Interact. 7:189-195.

Suzuki, M., Kuwata, S., Kataoka, J., Masuta, C., Nitta, C., and Takanami, Y. 1991. Functional analysis of deletion mutants of cucumber mosaic virus RNA 3 using an in vitro transcriptional system. Virology 183:106-113.

Takanami, Y. 1981. A striking change in symptoms on cucumber mosaic virus-infected tobacco plants induced by a satellite RNA. Virology 109:120-126.

Tousch, D., Jacquemond, M., and Tepfer, M. 1994. Replication of cucumber mosaic virus satellite RNA from negative sense transcripts produced either in vitro or in transgenic plants. J. Gen. Virol. 75: 1009-1014.

Tousignant, M. E., and Kaper, J. M. 1993. Cucumber mosaic virusassociated RNA 5. XIII. Opposite necrogenicities in tomato of variants with large 5' half insertion/deletion regions. Res. Virol. 144:349-360.

Vance, V. B. 1991. Replication of potato virus X RNA is altered in coinfections with potato virus Y. Virology 182:486-494.

White, J. T., Tousignant, M. E., Geletka, L. M., and Kaper, J. M. 1995. The replication of a necrogenic cucumber mosaic virus satellite is temperature-sensitive in tomato. Arch. Virol. 140:53-63.

Wu, G., and Kaper, J. M. 1992. Widely separated sequence elements within cucumber mosaic virus satellites contribute to their ability to induce lethal tomato necrosis. J. Gen. Virol. 73:2805-2812.

Wu, G., and Kaper, J. M. 1993. Requirement of 3'- terminal guanosine in (-)-stranded RNA for in vitro replication of cucumber mosaic virus satellite RNA by viral RNA-dependent RNA polymerase. J. Mol. Biol. 238:655-657.

Zhang, L., Kim, C. H., and Palukaitis, P. 1994. The chlorosis-induction domain of the satellite RNA of cucumber mosaic virus: Identifying sequences that affect accumulation and the degree of chlorosis. Mol. Plant-Microbe Interact. 7:208-213. 